\title{
La recuperación de las miniseries en España: análisis programático y textual
}

\author{
Recovery of miniseries in Spain: programmatic and textual analysis
}

\author{
Silvia García Mirón ${ }^{[a]}$, Diana Ramahí García ${ }^{[b]}$ \\ [a] Profesora de Publicidad y Relaciones Públicas en la Facultad de Ciencias Sociales y de la Comunicación de la Universidad de Vigo. \\ Pontevedra - España, e-mail: silviamiron@uvigo.es \\ ${ }^{[b]}$ Becaria de investigación del Ministerio de Ciencia e Innovación, forma parte del personal investigador en formación de la \\ Universidad de Vigo, Pontevedra - España, e-mail: dianaramahi@gmail.com
}

\section{Resumen}

Teniendo en cuenta las múltiples oscilaciones que experimenta el medio televisivo, entre otros, en el plano de los contenidos, el recurso continuado a un determinado producto en un período de tiempo concreto se vincula al presumible surgimiento de una tendencia programática que, susceptible de ser consolidada, acabe por definir su desarrollo. Si bien hay ciertas creaciones que han acabado por caracterizar y limitarse a una etapa, hay otras que han impreso su huella en la evolución televisiva en base a una emergencia episódica y una trayectoria irregular. Éste es el caso de las producciones seriadas de duración episódica limitada que, tras haber ocupado una modesta posición durante los últimos años, parecen haber comenzado a recuperar su lugar en las parrillas televisivas. Esta contribución pretende ahondar en las causas de esta reincorporación a través del análisis textual y programático de las creaciones emitidas por las principales emisoras de ámbito nacional en España durante los dos primeros trimestres del año 2010.

Palabras-clave: Miniseries. Estrategias de programación. Género. Narrativa audiovisual. Análisis.

\section{Abstract}

Taking into account the continuous variations of television contents, the persistent use of a product in a particular period of time may be linked to the emergence of a programmatic trend that, capable of being consolidated, may be able finally define its development. While there are some creations that have come to characterize and be confined to a 
phase, there are others that have printed their mark in television development by tracing an irregular path. This is the case of miniseries that, after occupying a modest position in recent years, are now on their way to regain prominence in the TV guides. The present paper aims at examining in greater detail the causes of the comeback of this format through textual and programmatic analysis of the main TV channels in Spain during the first semester of 2010.

Keywords: Miniseries. Guide strategies. Genre. Audiovisual narrative. Analysis.

\section{Introducción}

Los avances de programación realizados por las emisoras de alcance nacional para el último trimestre de 2010, parecen poner de manifiesto la continuidad y consolidación de una tendencia programática perfilada ya a lo largo de las últimas temporadas y fundamentada en la incorporación a las parrillas de productos seriados de duración episódica limitada. Producciones que, al margen de la diversidad de términos empleados por el ámbito profesional para su denominación, se adhieren de forma ajustada en base a la presencia de unos rasgos propios y homogéneos a lo que tradicionalmente se ha dado en llamar miniserie. Parece ser la presencia de una temporalidad y seriación características lo que diferencia e individualiza a este tipo de creaciones. De este modo, situadas a medio camino entre las producciones de largo metraje y emisión única realizadas para televisión, y las creaciones de ficción con un amplio número de entregas, se plantean estructuralmente en torno a episodios siendo, por lo general, su duración capitular inferior a la de otro tipo de productos seriados (BARROSO GARCÍA, 2002, p. 312).

La fórmula, que irrumpió en territorio nacional español durante los años 60 (GARCÍA DE CASTRO, 2002, p. 37-38), y vivió sucesivas etapas de esplendor en las décadas siguientes años 1970 y 1990 -, pasó a ocupar poco después del cambio de siglo una posición modesta en base a una naturaleza aparentemente no homologable con el estallido de lo que se ha dado en llamar "Telerrealidad". El discurrir temporal y las modificaciones producidas en el panorama televisivo entretanto, han acabado sin embargo por reabrir de forma generalizada el camino a un formato que, pese a su discontinuidad, cada cierto tiempo recobra vida (HUERTA FLORIANO; SANGRO COLÓN, 2007, p. 12-13).

Dada la complejidad del fenómeno televisivo, proveedor de entretenimiento al tiempo que maquinaria económica e industrial, son muy diversas las motivaciones que pueden sustentar la recuperación de producciones de estas características. Diversidad genética que se articula como eje de esta contribución.

\section{Materiales y métodos}

Dado que son múltiples los factores que pueden influir en la inserción de un determinado componente en la parrilla televisiva - adaptación de nuevas estrategias de programación, reorientación de los contenidos en busca de la aceptación popular, incremento de la rentabilidad de producción, cumplimiento de la legislación vigente, etc. - esta contribución pretende ahondar en las causas que motivan el asentamiento de una veta programática caracterizada por la producción y programación generalizada de miniseries por parte de las emisoras de ámbito nacional.

Para ello, y teniendo en cuenta la imposibilidad de abarcar el fenómeno en su totalidad, hemos optado por remitirnos al estudio a dos niveles narrativo y programático - de una muestra que parece resultar, al menos a priori, paradigmática a este respecto. Nos referimos en este caso, al conjunto de productos seriados de duración episódica limitada realizados y emitidos por las principales cadenas de ámbito nacional por audiencia, tanto de titularidad pública como privada-Televisión Española, Antena 3, Telecinco, Cuatro y La Sexta-, durante los dos primeros trimestres de 2010.

Esta acotación temporal, fundamentada en el inicio de una nueva temporada programática, coincidente en este caso, con la puesta en práctica de 
los cambios de financiación previstos para Televisión Española, ${ }^{1}$ y el final de temporada que supone el inicio de la programación estival, ha acabado por generar un corpus constituido por un total de seis producciones: El pacto, Adolfo Suárez el presidente, La piel azul, La Duquesa, Ojo por ojo y No soy como tú.

De este modo, la muestra audiovisual y el conjunto de las parrillas de programación en las que se inserta el corpus analizado, así como el presumible y necesario recurso a publicaciones especializadas, se articulan como sustrato investigativo de partida tanto para el esclarecimiento del objeto de esta investigación, como para la contribución a la identificación y caracterización del género en España.

Teniendo en cuenta el cariz multifacético del fenómeno abordado, no ha de resultar extraño el carácter necesariamente poliédrico que adopta esta aproximación. Se engarzan así el vaciado bibliográfico y el análisis de contenido (KRIPPENDORF, 1990, p. 28) de materiales preexistentes relacionados con el objeto de estudio en sentido amplio, con el análisis fílmico (AUMONT; MARIE, 1999, p. 18) - en relación al contenido narrativo, la materialización audiovisual y la conformación narratológica de las piezas como obras autónomas - y su estudio como elemento programático (CORTÉS LAHERA, 2001, p. 217-240) - observación de las estrategias de programación y de los resultados de audiencia.

\section{Resultados}

\section{Caracterización de las miniseries: contenido, bases visuales y sonoras, y estructuras narrativas}

Dado que narrar una historia supone necesariamente operar una serie de elecciones que abarcan desde la elección de un medio expresivo hasta la adopción de un determinado punto de vista, o la disposición de los acontecimientos en un orden que puede coincidir o no con el estrictamente cronológico, no ha de resultar extraño que en el estudio del filme se tengan en cuenta la historia base, la enunciación que se hace de la misma, y que admite múltiples configuraciones posibles, y el soporte discursivo, caracterizado en el caso del cine por la heterogeneidad de sus componentes (NEIRA PIÑEIRO, 2003, p. 27-28).

\section{Análisis del contenido narrativo}

En el plano del contenido, con independencia de su materialización, las obras que conforman la muestra analizada se caracterizan por la heterogeneidad, adoptando temáticas diversas que oscilan, al tiempo y también, en su nivel de implicación con hechos históricos de base.

Así, Adolfo Suárez el presidente y la Duquesa adoptan la forma de la biografía filmada, centrándose en pasajes de la vida de personajes que resultan conocidos para el público. En el primer caso, y como indica lo homónimo de su título, la pieza se centra en la vida de Adolfo Suárez, considerado el primer Presidente democrático del gobierno español, y primer ministro entre 1976 y 1981. La pieza intenta abarcar la amplia totalidad de la vida política de su protagonista, desde su incorporación a la actividad en su juventud, hasta su dimisión al frente de la presidencia gubernamental, haciendo especial hincapié en el golpe de estado del 23 de Febrero de 1981. La Duquesa, por su parte, relata la vida de Cayetana Fitz-James Stuart, aristócrata española que ostenta, entre otros muchos, el título de XVIII Duquesa de Alba de Tormes desde 1955. El filme, que toma como punto de partida su nacimiento, da cuenta de su trayectoria vital hasta los últimos años setenta, y en concreto hasta los albores de su segundo matrimonio.

Elpacto y Ojo por ojo, aunque se encuentran lejos del retrato, siguen conservando una estrecha relación con un sustrato histórico preexistente.

\footnotetext{
1 Durante el desarrollo de esta investigación Televisión Española (el canal público de televisión en España) ya gozaba de su nueva pretensión de servicio público con una única fuente de financiación dejando atrás la doble entrada con cargo a los presupuestos generales del Estado y la venta publicitaria tal y como se había recomendado en el Informe para la Reforma de los Medios de Comunicación de Titularidad del Estado (el "Informe de Sabios"). AZURMENDI ADARRAGA, A. La reforma de la televisión pública española. Valencia: Tirant Lo Blanch, 1997.
} 
Así, Elpacto obtiene su base narrativa de una historia real ubicada en un marco geográfico y temporal diferente-Massachusetts, 2008 - sobre la que, en su traslación fílmica, se realizan modificaciones sustanciales y deliberadas. La miniserie relata así el peculiar acuerdo al que llegan una serie de adolescentes para quedarse embarazadas de forma simultánea, abarcando el proceso de incubación, gestación y parto de las protagonistas, y las vicisitudes y reacciones que provoca el hecho. En el caso de Ojo por ojo el sustrato histórico se convierte en el telón de fondo y en causa desencadenante de la trama principal desarrollada por el filme. Así, en el marco del anarquismo, la lucha sindical y los enfrentamientos sociales de la Barcelona de los años veinte, un joven obrero que trabaja en una fábrica textil, con las pretensiones de vengar la muerte de su hermano acaba involucrándose en el movimiento anarquista y secuestrando a la hija de su antiguo patrón.

Por su parte La piel azul y No soy como tú, carecen de base real, convirtiéndose en ambos casos en producciones con un sustrato marcadamente ficticio. La piel azul relata las vicisitudes y nefastas consecuencias que, para un grupo de jóvenes acomodados, acaba por tener lo que en principio se perfila como un idílico viaje en barco. Por su parte, No soy como tú, se adhiere al auge actual de la temática vampírica y traza un peculiar esbozo de la adolescencia, marcado por los conflictos paterno-filiales, la amistad o las relaciones sentimentales, en un contexto caracterizado por la convivencia no siempre armónica - entre vampiros y humanos.

Pero si, como vemos, es la pluralidad lo que define el contenido, esta marcada diversidad se neutraliza en el proceso de materialización. Al margen de su creación para televisión, medio con un discurso propio, ${ }^{2}$ las piezas analizadas optan a este respecto, por seguir de forma mayoritaria - aunque como veremos con intrusiones y matices - los presupuestos del clasicismo representacional cinematográfico, ${ }^{3}$ siempre teniendo en cuenta la simplificación que supone la traslación televisiva de sus pautas (SÁNCHEZ NAVARRO, 2006, p. 145).

\section{Análisis de las bases visuales y sonoras}

Así, teniendo en cuenta que a diferencia de lo que ocurre con otros modos de representación fílmicos, para el clasicismo narrar una historia es la preocupación formal básica, la planificación adopta de forma generalizada elecciones medias, tanto en lo que se refiere a la angulación como a la amplitud, adaptándose, con independencia de las presumibles pretensiones autorales, al referente real.

Bien es cierto que un análisis pormenorizado del cuerpo textual de algunas de las piezas analizadas pone de manifiesto el despliegue recurrente de una mirada concreta - es el caso de la visualización general y ascendente que ofrece La Duquesa, el gusto por el detalle presente en La piel Azul o el recurso constante a la amplitud del encuadre en No soy como tú u Ojo por ojo -. Pautas formales que, sin embargo, lejos de pretender hacer emerger a la imagen, adquieren un carácter semántico en relación a la historia relatada o funcional en lo que se refiere a la puesta en escena.

Las facturas cromáticas y lumínicas adquieren un carácter heterogéneo entre las piezas en base a su estrecha vinculación al - divergente contenido narrativo abordado, tendiendo sin embargo a la homogeneidad en cada uno de los textos. Al margen del carácter dominante de esta continuidad perceptiva, en alguna de las piezas se opta por recurrir también de forma relativamente manifiesta al potencial significante de los elementos fotográficos, produciéndose variaciones en función de la evolución del relato. Resulta paradigmático a

\footnotetext{
Remitimos al lector interesado a: GONZÁLEZ REQUENA, J. El discurso televisivo: espectáculo de la posmodernidad. Madrid: Cátedra, 1988.

Así, de acuerdo con Burch (1985, p. 226) este modo de representación no es otra cosa que una construcción basada en la linealización de los significantes y en el carácter clausurado de la diégesis; en la producción de la imagen como espacio habitable y de la totalidad diegética como entorno; en la "presencia", la centralidad y la tridimensionalidad del efecto de persona y en la voz sincrónica como garantía de todo ello. Para ahondar en esta temática puede consultarse la obra monográfica al respecto de BORDWELL, D.; STAIGER, J.; THOMPSON, K. El cine clásico de Hollywood. Estilo cinematográfico y modo de producción hasta 1960. Barcelona: Paidós, 1997.
} 
este respecto el caso de La piel azul, filme en el que el empeoramiento de las circunstancias en las que se encuentran los protagonistas va estrechamente ligado a un ensombrecimiento visual, o No soy como tú, en la que las modificaciones perceptivas a este respecto contribuyen a la identificación de los pasajes oníricos que contiene la pieza.

Se convierte también en destacable en base a su regularidad - y sus connotaciones postmodernas - la presencia en los cuerpos textuales de las piezas de otras texturas audiovisuales, o la aparición metatextual de la propia pantalla televisiva. ${ }^{4}$ Así, en El pacto se otorga cierto protagonismo visual a la imagen digital a través de la mostración sistemática - o la evocación visual - de las pantallas del ordenador personal y del teléfono móvil. El relato de Nadie como tú justifica, por su parte, la incorporación de imágenes con un resultado visual que remite directamente a las cámaras de seguridad, mientras el marco televisivo aparece con asiduidad en Adolfo Suárez, el presidente.

$\mathrm{Al}$ margen de estas digresiones, y en consonancia con la opción por la imperceptibilidad de la técnica mencionada, se opta por soluciones de continuidad tan convencionales como - y en consecuencia - visualmente imperceptibles - la adhesión por corte y residualmente la fusión o el encadenado de los cuadros. El montaje, por su parte, adquiere un carácter analítico fundamentándose en la transparencia y en la continuidad aparente de los planos. La puesta en serie sigue así la atención natural del espectador, haciendo que su deseo de conocer acabe por encubrir la fisura visual.

En base a la naturalidad aparente y la limitación significante de estas elecciones, es finalmente la puesta en escena la que sostiene parte importante del peso narrativo, ejerciendo un papel sustancial en una ambientación que resulta sustancial, bien en base a su diacronía temporal respecto al presente - La Duquesa, Adolfo Suárez, el presidente y Ojo por ojo - bien para la creación de la atmósfera que sustenta el universo diegético - No soy como tú.

\section{Análisis de las estructuras narrativas ${ }^{5}$}

En base al ya señalado asentamiento expresivo de las piezas en el clasicismo representacional, no ha de extrañar que una parte de la tan narrativamente eficaz convencionalidad presente en el plano eminentemente formal, imprima también sus huellas en la enunciación narrativa.

Así, al margen del carácter eminentemente personal que adquieren algunos relatos, las piezas optan en su totalidad por el empleo de una focalización omnisciente, dejando que esa omnisciencia sea más evidente en unas ocasiones que en otras. Del mismo modo se opta por la pluralidad espacial - presencia de escenarios múltiples -, y la frecuencia singulativa - los hechos acontecidos aparecen en el relato una única vez. Es en el plano de la duración y el orden, manifiestamente manipulados en relación a la historia de base, donde se perciben las singularidades. ${ }^{6}$

Aunque ciertas obras de la muestra analizada optan por la ordenación lineal vectorial de los acontecimientos - es el caso de La Duquesa, La piel azul, Ojo por ojo o No soy como tú - en otras ocasiones se opta por la alteración intencionada de la sucesión natural de los hechos. En el caso de El pacto la pieza, que comienza in media res, se combina el orden cronológico con sucesivas analepsis que explican las circunstancias que han llevado a la situación de partida. Adolfo Suárez, el presidente enlaza, por su parte

\footnotetext{
${ }^{4}$ De acuerdo con Quintana (2004, p. 4), en el panorama cinematográfico, el eclecticismo que define la postmodernidad estuvo acompañado de la presencia de otras texturas provenientes de sectores audiovisuales colindantes como la publicidad o los videoclips. 5 Nos remitimos aquí a la adaptación que se ha realizado al ámbito cinematográfico del estandarizado sistema empleado por Gérard Genette. Así, tomando como punto de partida la división realizada por Todorov (1966), el autor planteó una metodología tripartita que pretendía abarcar en su totalidad la problemática existente entre el contenido narrativo y el texto haciendo referencia a: el tiempo - las posibles alteraciones respecto a la cronología factual -, el modo - la regulación de la información narrativa - , y la voz, la instancia narrativa y sus huellas - (GENETTE, 1989). Para ahondar en esta perspectiva puede consultarse: GAUDREAULT A.; JOST, F. El relato cinematográfico: cine y narratología. Barcelona: Paidós, 1995.

Aspecto que no difiere en cualquier caso con las pautas del modelo clásico, tal y como señala Bordwell (1998, p. 47) "Con mayor frecuencia, la narración clásica emplea estrategias características para manipular el orden y la duración de la historia”.
} 
dos relatos cronológicamente distanciados y temporalmente divergentes que avanzan en orden hasta enlazarse. Por una parte la trayectoria del protagonista desde su juventud hasta su dimisión como Primer Ministro. Por la otra los sucesos acaecidos durante el golpe de estado del 23 de Febrero de 1981.

Respecto a la duración, y como viene siendo habitual en el ámbito cinematográfico para hacer viable el relato de historias de temporalidades diversas, se recurre a mecanismos que permiten mostrar los sucesos importantes y evitar o acortar los intervalos que los separan. La elipsis - de amplitudes diversas, determinadas o indeterminadas - se convierten en una constante en las piezas analizadas. Dado que en ninguno de los casos el tiempo del relato y de la historia se identifican, los mecanismos de elisión hacen viable la narración de acontecimientos que ocurren en décadas - La duquesa, Adolfo Suárez, el presidente-, meses - Elpacto, Ojo por Ojo-, o días - La piel azul, No soy como tú - en dos horas y media de metraje. Resulta también palpable en ocasiones, aunque notablemente inferiores en número, el empleo de otros mecanismos de condensación, como es el caso del sumario en Adolfo Suárez el presidente.

En cualquier caso, y aunque la tendencia se orienta de forma manifiesta hacia el acortamiento narrativo, bien es cierto que en alguna de las piezas se opta por un tratamiento invertido de la duración temporal mediante una actuación sobre la velocidad de reproducción de los fotogramas. Se obtienen así, con presumibles pretensiones estilísticas, más o menos justificadas, imágenes que, sin alcanzarla, tienden a la estasis. La piel azul, y en concreto el primer tercio de su metraje, resultan paradigmáticos a este respecto.

\section{Estrategias de programación de las miniseries: localización, formato y audiencia}

Siguiendoa Cortés Lahera (2001,p. 217-240), distinguimos tres clasificaciones posibles en las que podemos encuadrar las estrategias de programación: estrategia de localización - atendiendo a la ubicación de los programas en la parrilla de programación -; estrategia de formato - relacionada con el contenido de los programas o con su formato -; y estrategia de caracteres - si afecta a los conductores de programas, protagonistas de series o a la misma trama que elaboran los guionistas, en el caso de la ficción.

Para esta investigación llevaremos a cabo un análisis de tipo descriptivo centrándonos en la estrategia de localización de estos programas en la parrilla de programación, en su formato e identificando aquellas acciones programáticas que siguen las emisoras televisivas objeto de análisis en relación con este producto. Asimismo, atenderemos a otro tipo de parámetros cómo son la identificación de la competencia, la audiencia obtenida o los programas que rodean la emisión de cada uno de los capítulos de las miniseries que conforman la muestra.

\section{Análisis de las estrategias de localización de las miniseries en la parrilla de programación}

Comenzando con el análisis de las acciones programáticas ejecutadas en base a las estrategias de ubicación de estos productos audiovisuales en la parrilla, nos encontramos con ciertas similitudes en algunos casos o esquemas que se repiten en el caso de una emisora y que definen su estilo e identidad.

Para el análisis de programación, partimos de la premisa esencial de que este formato ofrece características que son contrarias al criterio de programación horizontal por su falta total de seriación. No obstante, si tenemos en consideración la ubicación de las miniseries en la parrilla obtenemos que éstas acostumbran a ser emitidas tras otro contenido que se programa en la franja de acceso a prime time, salvo en el caso de Televisión Española con Ojo por ojo y en Telecinco con la emisión de La Duquesa, productos programados tras los servicios informativos. Estos access prime time se configuran en torno al humor, ya sea un programa de entretenimiento a base de imitaciones o chistes - La escobilla nacional o El Club del Chiste, ambos en Antena 3 - o bien en forma de series de corta duración - La pecera de Eva en Telecinco o Padres en Antena 3. Esta estrategia es conocida como Lead-in y se relaciona con estos programas

\footnotetext{
La duración real de las piezas es homogénea oscilando entre las dos horas y las tres horas de metraje, siendo divididas en dos capítulos de entre dos horas y hora y media.
} 
de acceso, cuya misión consiste en conseguir un importante número de espectadores que puedan a continuación unirse al siguiente programa.

Pese a esto, todas las miniseries se programan en prime time, entre las $22 \mathrm{~h}$ y las $22 \mathrm{~h} 30$, con la salvedad del segundo episodio de No soy como tú, emitido después de la película Crepúsculo (Catherine Hardwicke, 2008), a las 00:30 horas. La proximidad de género - ficción sobre vampiros - junto con el éxito de taquilla del film y el estreno de la tercera película de la saga, Eclipse (2010), durante esos días, sirvió como estrategia del canal al modificar su anterior horario buscando un arrastre de la audiencia. El Blocking, tal y como se denomina, es una acción programática por la cual se determina que, "en horas concretas o franjas horarias, dos programas de características similares, emitidos uno detrás del otro, pueden crear e incluso aumentar la audiencia, produciendo un bloque compacto de idéntico target" (CORTÉS LAHERA, 2001, p. 229). La finalidad es la unión de productos con características similares, como ocurre en el caso expuesto, pues así podría conseguirse un flujo de audiencia homogéneo.

Por otra parte, TVE1 y Telecinco - aunque únicamente con la emisión de La Duquesa-siguieron una estrategia de Bridging, comenzando el programa antes que el del competidor - no incluyendo un producto previo de access prime time -, tratando de que en estos minutos la audiencia ya se enganche al contenido y no cambie más tarde de canal - en estos casos hablamos de prácticamente media hora antes. Pero sería en los programas de emisión posterior a la miniserie donde vislumbramos una mayor diversidad de formatos: cine, series, documentales - tanto relacionados con el contenido de la miniserie, como con una temática diferente-, debates e incluso programas de entrevistas.

Tabla 1 - Estrategias de localización de las miniseries en la parrilla de programación

\begin{tabular}{|c|c|c|c|}
\hline Miniserie & Emisión & Programa previo & Programa posterior \\
\hline \multirow{2}{*}{ El pacto } & 10 Enero & La pecera de Eva (serie) & Gran Hermano: el debate. \\
\hline & 17 Enero & La pecera de Eva (serie) & Gran Hermano: el debate. \\
\hline \multirow{2}{*}{$\begin{array}{l}\text { Adolfo Suárez, } \\
\text { el presidente }\end{array}$} & 27 Enero & Padres (serie) & Suárez, un político para la historia (documental) \\
\hline & 3 Febrero & Padres (serie) & Adolfo Suárez, la transición (documental) \\
\hline \multirow{2}{*}{ La piel azul } & 14 Marzo & La escobilla nacional (humor) & Invisibles (documental) \\
\hline & 21 Marzo & La escobilla nacional (humor) & Retratos de una obsesión (cine) \\
\hline \multirow{2}{*}{ La duquesa } & 13 Abril & Informativos Telecinco & $\begin{array}{l}\text { Hormigas blancas: especial sobre Cayetana de Alba (I) } \\
\text { (debate y reportajes) }\end{array}$ \\
\hline & 20 Abril & Informativos Telecinco & $\begin{array}{l}\text { Hormigas blancas: especial sobre Cayetana de Alba (II) } \\
\text { (debate y reportajes) }\end{array}$ \\
\hline \multirow{2}{*}{ Ojo por ojo } & 14 Junio & Telediario 2 y El Tiempo & Volver con... Rosario Pardo (entrevistas) \\
\hline & 21 Junio & Telediario 2 y El Tiempo & Volver con... Ángel Nieto (entrevistas) \\
\hline \multirow[b]{2}{*}{ No soy como tú } & 17 Junio & El Club del Chiste (humor) & Murciélagos (cine) \\
\hline & $1^{\mathrm{o}}$ Julio & Crepúsculo (cine) & Sin rastro (serie) \\
\hline
\end{tabular}

Fuente: Dados de la Búsqueda. 
En cuanto a la estrategia de localización utilizada destacan los dos casos de biopics, ya que tras la emisión de cada uno de los dos episodios de La Duquesa o de Adolfo Suárez, el presidente, Telecinco por un lado y Antena 3 por el otro programaron un especial con documentales y reportajes de estas personalidades tratando de conseguir también e arrastre de audiencia. En el caso de Telecinco la incidencia es mayor pues se incluyeron entrevistas y debates y no únicamente la emisión de un documental. No se utiliza, por tanto, la estrategia denominada Hammock ó Sándwich programming, que consiste en colocar un producto nuevo entre otros dos de probada eficacia. En realidad algunos de los contenidos que se utilizan de accessprime time también son programas de reciente llegada a las parrillas y los programas posteriores a la miniserie son, en la gran mayoría, programas de baja audiencia, debido fundamentalmente a las horas de emisión, aunque también por sus contenidos reposiciones de películas, entrevistas con personajes que no tienen demasiado gancho, etc.

\section{Relación entre la estrategia de formato de las miniseries y los resultados de audiencia}

Proponemos el análisis de la competencia de estas miniseries atendiendo a los resultado de audiencia obtenidos por los principales contenidos de cada una de las jornadas que configuran la muestra - es decir, aquellos días en los que se emitieron alguno de los capítulos de las miniseries - en la franja de prime time.

Tabla 2 - Relación de programas y audiencias en prime time durante los días de emisión de las miniseries ${ }^{8}$

\begin{tabular}{|c|c|c|c|c|c|c|c|c|c|c|}
\hline Día & TVE1 & A & Antena 3 & A & Telecinco & A & Cuatro & $\mathbf{A}$ & La Sexta & A \\
\hline $\begin{array}{l}10 \text { Enero } \\
\text { domingo }\end{array}$ & $\begin{array}{l}\text { La película de } \\
\text { la semana: La } \\
\text { búsqueda }\end{array}$ & 29,1 & $\begin{array}{l}\text { Pánico en el } \\
\text { plató }\end{array}$ & 11,1 & El pacto & 18,2 & $\begin{array}{l}\text { Desafío } \\
\text { extremo }\end{array}$ & 6,7 & $\begin{array}{l}\text { Cine: Antz } \\
\text { ¿Qué más } \\
\text { quisiera yo! }\end{array}$ & $\begin{array}{l}5,9 \\
3,8\end{array}$ \\
\hline $\begin{array}{l}17 \text { Enero } \\
\text { domingo }\end{array}$ & $\begin{array}{l}\text { La película } \\
\text { de la semana: } \\
\text { Hollywood, } \\
\text { departamento } \\
\text { de homicidios }\end{array}$ & 24,0 & $\begin{array}{l}\text { La escobilla } \\
\text { nacional } \\
\text { Pánico en el } \\
\text { plató }\end{array}$ & $\begin{array}{l}18,2 \\
6,5\end{array}$ & El pacto & 22,3 & $\begin{array}{l}\text { Fama, ja } \\
\text { bailar! }\end{array}$ & 4,4 & $\begin{array}{l}\text { El mentalista. } \\
\text { ¿Quién vive } \\
\text { ahî? }\end{array}$ & $\begin{array}{l}7,5 \\
7,2\end{array}$ \\
\hline $\begin{array}{l}27 \text { Enero } \\
\text { miércoles }\end{array}$ & $\begin{array}{l}\text { Comando } \\
\text { actualidad } \\
\text { (2 programas) }\end{array}$ & $\begin{array}{l}15,3 \\
16,5\end{array}$ & $\begin{array}{l}\text { Adolfo } \\
\text { Suárez, el } \\
\text { presidente }\end{array}$ & 15,6 & $\begin{array}{l}\text { Gran } \\
\text { Hermano }\end{array}$ & 29,5 & House & 8,1 & $\begin{array}{l}\text { Cine: } \\
\text { Rounders }\end{array}$ & 6,2 \\
\hline $\begin{array}{l}3 \text { Febrero } \\
\text { miércoles }\end{array}$ & $\begin{array}{l}\text { Comando } \\
\text { actualidad } \\
\text { (2 programas) }\end{array}$ & $\begin{array}{l}13,2 \\
12,5\end{array}$ & $\begin{array}{l}\text { Adolfo } \\
\text { Suárez, el } \\
\text { presidente }\end{array}$ & 16,2 & $\begin{array}{l}\text { Gran } \\
\text { Hermano: el } \\
\text { reencuentro }\end{array}$ & 24,5 & $\begin{array}{l}\text { Hay alguien } \\
\text { ahí }\end{array}$ & 5,5 & $\begin{array}{l}\text { Bones } \\
\text { ( } 2 \text { capítulos) }\end{array}$ & $\begin{array}{l}10,4 \\
8,1\end{array}$ \\
\hline $\begin{array}{l}14 \text { Marzo } \\
\text { domingo }\end{array}$ & $\begin{array}{l}\text { La película } \\
\text { de la semana: } \\
\text { Déjà vu. }\end{array}$ & 27,6 & La piel azul & 13,0 & I love Escassi. & 6,6 & $\begin{array}{l}\text { Desafío } \\
\text { extremo } \\
\text { Perdidos } \\
\text { en la tribu. }\end{array}$ & $\begin{array}{l}5,8 \\
8,3\end{array}$ & $\begin{array}{l}\text { El mentalista } \\
\text { ( } 2 \text { capítulos) }\end{array}$ & $\begin{array}{l}7,7 \\
7,7\end{array}$ \\
\hline $\begin{array}{l}21 \text { Marzo } \\
\text { domingo }\end{array}$ & $\begin{array}{l}\text { La película de } \\
\text { la semana: } \\
\text { En el valle de } \\
\text { Elah }\end{array}$ & 21,5 & La piel azul & 12,0 & $\begin{array}{l}\text { Aída } \\
\text { (2 capítulos) }\end{array}$ & $\begin{array}{l}13,3 \\
14,3\end{array}$ & $\begin{array}{l}\text { Perdidos } \\
\text { Perdidos } \\
\text { en la tribu }\end{array}$ & $\begin{array}{l}4,9 \\
7,6\end{array}$ & $\begin{array}{l}\text { El mentalista } \\
\text { ( } 2 \text { capítulos) }\end{array}$ & $\begin{array}{l}8,1 \\
7,1\end{array}$ \\
\hline $\begin{array}{l}13 \text { Abril } \\
\text { martes }\end{array}$ & $\begin{array}{l}\text { Españoles } \\
\text { en el mundo. }\end{array}$ & 14,1 & Karabudjan & 10,5 & La duquesa & 21,5 & House & 11,1 & $\begin{array}{l}\text { Cine: } \\
\text { Hora punta }\end{array}$ & 7,7 \\
\hline
\end{tabular}

\footnotetext{
${ }^{8}$ Los datos de audiencias (A) han sido extraídos del portal español sobre información televisiva FormulaTV.com. Se presentan en \%.
} 
Tabla 2 - Relación de programas y audiencias en prime time durante los días de emisión de las miniseries

\begin{tabular}{|c|c|c|c|c|c|c|c|c|c|c|}
\hline Día & TVE1 & A & Antena 3 & A & Telecinco & A & Cuatro & A & La Sexta & A \\
\hline $\begin{array}{l}20 \text { Abril } \\
\text { martes }\end{array}$ & $\begin{array}{l}\text { Españoles } \\
\text { en el mundo. }\end{array}$ & 14,9 & Karabudjan & 9,5 & La duquesa & 22,8 & House & 11,7 & $\begin{array}{l}\text { Cine: } \\
\text { El guerrero } \\
n^{\circ} 13\end{array}$ & 8,4 \\
\hline $\begin{array}{l}14 \text { Junio } \\
\text { lunes }\end{array}$ & Ojo por ojo & 14,9 & Gavilanes & 13,2 & $\begin{array}{l}\text { CSI Las Vegas } \\
\text { (2 capítulos) }\end{array}$ & $\begin{array}{l}12,8 \\
12,1\end{array}$ & $\begin{array}{l}\text { Callejeros } \\
\text { viajeros }\end{array}$ & 10,7 & $\begin{array}{l}\text { Cine: } \\
\text { El mundo } \\
\text { nunca es } \\
\text { suficiente }\end{array}$ & 10,3 \\
\hline $\begin{array}{l}21 \text { Junio } \\
\text { lunes }\end{array}$ & Ojo por ojo & 11,2 & Gavilanes & 12,6 & $\begin{array}{l}\text { NCSI Los } \\
\text { Ángeles }\end{array}$ & 15,5 & $\begin{array}{l}\text { Callejeros } \\
\text { viajeros }\end{array}$ & 11,3 & $\begin{array}{l}\text { Cine: La } \\
\text { última } \\
\text { fortaleza }\end{array}$ & 11,6 \\
\hline $\begin{array}{l}17 \text { Junio } \\
\text { jueves }\end{array}$ & $\begin{array}{l}\text { Gran reserva } \\
\text { Cine: Cámara } \\
\text { sellada }\end{array}$ & $\begin{array}{l}21,8 \\
14,6\end{array}$ & $\begin{array}{l}\text { No soy } \\
\text { como tú }\end{array}$ & 8,8 & Supervivientes & 18,6 & $\begin{array}{l}\text { Castle } \\
\text { ( } 2 \text { capítulos) }\end{array}$ & $\begin{array}{l}7,4 \\
9,0\end{array}$ & $\begin{array}{l}\text { ¿Quién } \\
\text { vive ahí? } \\
\text { Mujeres ricas }\end{array}$ & $\begin{array}{l}8,0 \\
9,9\end{array}$ \\
\hline $\begin{array}{l}1^{\circ} \text { Julio } \\
\text { jueves }\end{array}$ & $\begin{array}{l}\text { Gran reserva } \\
\text { Cine: Lo dice } \\
\text { Georgia }\end{array}$ & $\begin{array}{l}21,2 \\
14,4\end{array}$ & $\begin{array}{l}\text { Crepúsculo } \\
\text { No soy } \\
\text { como tú }\end{array}$ & $\begin{array}{l}18,9 \\
10,5\end{array}$ & $\begin{array}{l}\text { Supervivientes } \\
\text { Resistiré, } \\
\text { ¿vale? }\end{array}$ & $\begin{array}{l}15,9 \\
22,2\end{array}$ & $\begin{array}{l}\text { Castle } \\
\text { ( } 2 \text { capítulos) }\end{array}$ & $\begin{array}{l}6,8 \\
6,5\end{array}$ & $\begin{array}{l}\text { ¿Quién vive } \\
\text { ahí? } \\
\text { Mujeres ricas }\end{array}$ & $\begin{array}{l}5,9 \\
7,6\end{array}$ \\
\hline
\end{tabular}

Fuente: Dados de la Búsqueda.

En relación con la estrategia de formato, extraemos dos ideas. La primera de ellas se estructura en torno a la preferencia del género por parte de unas emisoras concretas. De acuerdo con la muestra, las miniseries son un formato realizado esencialmente por dos cadenas de televisión: las dos principales emisoras privadas atendiendo a los niveles de audiencia: Antena 3, que emitió en el periodo analizado tres miniseries, y Telecinco, que participa en la muestra con dos productos de este tipo. No obstante, se suma el principal canal de Televisión Española - TVE1 - con un producto de este tipo, Ojo por ojo. Por otra parte, obtenemos que este formato se emite prácticamente siempre bajo el mismo esquema de programación: los dos capítulos son emitidos en semanas consecutivas y el mismo día de la semana. La excepción se encuentra en No soy como tú pues se dejan pasar quince días entre la primera y la segunda emisión. Aparentemente no se encuentra ninguna razón de fuerza mayor, pues no se programó ningún evento de carácter especial, sino la película Alejandro Magno (OLIVER STONE, 2004). Lo más adecuado es entender este tiempo de retraso como una espera que hiciese coincidir el final de la miniserie con la proyección de Eclipse (David Slade, 2010) - la tercera película de la saga Crepúsculo - que se produjo en las salas cinematográficas el 30 de junio.
En cuanto a los resultados de audiencia, podemos afirmar que algunas miniseries sí funcionaron bien, consiguiendo ser incluso líderes de audiencia en prime time - como ha sido el caso de La Duquesa o el primero de los capítulos de Ojo por ojo. Sin embargo, en el resto de casos han sido la ficción La película de la semana de Televisión Española emitida los domingos o la serie Gavilanes - junto con el reality show Gran Hermano los que han superado los resultados alcanzados por este producto.

El pacto ha conseguido situarse como la segunda opción de la audiencia en sus dos capítulos $18,2 \%$ de share en su estreno y $22,3 \%$ en su segunda emisión -, siendo superada por el cine de Televisión Española, que en las noches de los domingos programa estrenos, gran parte de ellos, éxitos de Hollywood - $\mathrm{La}$ Búsqueda (Jon Turteltaub, 2004) y Hollywood, departamento de homicidios (Ron Shelton, 2003) han sido los casos de estas dos semanas de enero.

La miniserie Adolfo Suárez, elpresidente, fue-al igual que Elpacto - el segundo programa más visto de las noches de los miércoles 27 de enero y 3 de febrero $-15,6 \%$ y $16,2 \%$. La ganadora en cuanto a audiencia de estos días resultó Gran Hermano, con un $29,5 \%$ de share y un $24,5 \%$ en el estreno de su edición centrada en un reencuentro de antiguos concursantes, que coincidió con la emisión del segundo 
episodio de la miniserie. Comando actualidad, programa de reportajes en TVE1, le siguió muy de cerca.

La piel azul, a pesar de situarse también en segundo lugar en cuanto al número de espectadores que la siguieron - 13,0\% y 12,0\% - no alcanzó las cifras de los casos anteriores. Nuevamente, los largometrajes programados por TVE1 - Déjà vu (Tony Scott, 2006), 27,6\% y En el valle de Elah (Paul Haggis, 2007), 21,5\% - superaron con creces la emisión de la miniserie, asentando los intereses de los telespectadores por la ficción americana.

En cuanto al biopic sobre Cayetana de Alba, La Duquesa, sí consiguió dominar las noches de los martes 13 y 20 de abril $-21,5 \%$ y $22,8 \%$. No solo aumentó su share, sino que produjo el arrastre de audiencia al programa siguiente de debates y reportajes sobre La Duquesa de Alba que emitió Telecinco. Ni el programa documental Españoles en el Mundo de TVE1, ni la serie de reciente estreno de Antena 3, Karabudjan, consiguieron imponerse a la miniserie.

En lo que respecta a las jornadas de los lunes 14 y 21 de junio, durante las que se emitieron los dos capítulos de la miniserie histórica Ojo por ojo, las audiencias estuvieron muy repartidas. A pesar de todo, consiguió liderar la noche de su estreno $-14,9 \%$-, seguida muy de cerca por las series Gavilanes y CSI Las Vegas. Pero en su segundo episodio fue superada por el estreno de NCSI Los Ángeles - favorecida por la retransmisión previa del partido del Mundial de Fútbol de Sudáfrica España-Honduras, que consiguió en la franja horaria de 20:30 a 22:30 un 70\% de share-, la serie Gavilanes e incluso Callejeros Viajeros. El caso de la miniserie No soy como tú ha sido el que ha conseguido los resultados de audiencia más bajos de la muestra analizada $-8,8 \%$ y $10,5 \%$. La serie de Televisión Española Gran reserva junto con la película emitida después - Cámara sellada (James Foley, 1996) en un caso y Lo dice Georgia (Garry Marshall, 2007) en el otro - y el reality show de Telecinco Supervivientes fueron las preferencias de los espectadores.

\section{Consideraciones finales}

La programación recurrente de determinados productos televisivos en periodos de tiempo concretos parece adquirir un carácter sintómatico en relación a la caracterización y evolución del medio. De este modo, en nuestro caso, el incremento de la presencia en las parrillas nacionales de producciones de ficción seriadas con un número de episodios limitado esbozaba, a priori y aparentemente, una tendencia incipiente orientada a la recuperación de la miniserie como componente programático.

Dado el carácter peculiar y cronológicamente irregular de este género, nuestra investigación, fundamentada en el estudio multiperspectivista - programático, formal y de contenido - de las miniseries emitidas en las principales cadenas de alcance nacional en los dos primeros tercios del año 2010, pretendía aproximarse tanto a las posibles causas de esta "reinserción televisiva" como a las características que se le habían infundido al producto en su adaptación a la contemporaneidad inmediata.

El análisis de las piezas como obras autónomas ha puesto de manifiesto la heterogeneidad del corpus estudiado limitando la fundamentación formal o argumental de esta ola programática. Así, las creaciones examinadas se caracterizan por la diversidad argumental, la vinculación variable en relación a hechos históricos de base, y una convencionalidad formal-siempre con matices-que reduce las posibilidades de impacto fundamentadas en la espectacularidad visual y limita las marcas estilísticas atribuibles a un autor o cadena emisora.

Por su parte, la aproximación a su estatus como componente televisivo, ha definido de forma general a las realizaciones analizadas por una extrema limitación episódica que reduce su seriación a dos capítulos, su emisión en el mismo día de semanas sucesivas, su programación en franja nocturna de máxima audiencia - prime time -, y unos resultados variables en cuanto a audiencia que parecen excluir la obtención de cuota de pantalla como criterio de programación.

Así, todo parece indicar que la producción y programación recurrente de miniseries durante los últimos meses semeja responder a fundamentos que van más allá de la transmisión de un determinado contenido o la obtención de audiencia, y que pueden relacionarse, como esperamos estudiar en posteriores investigaciones, con la rentabilidad del género, la fidelización por parte de la emisora o la satisfacción de una demanda del público. 


\section{Agradecimientos}

Aportación realizada en el marco del Programa para la Formación de Profesorado Universitario, FPU, de la Secretaría de Estado de Universidades e Investigación. Ministerio de Ciencia e Innovación.

\section{Referencias}

ADOLFO SUÁREZ el Presidente. Dirección: Sergio Cabrera. España: Antena 3 Films; Europroducciones, 2010. 1 DVD (150 min).

ALEJANDRO Magno. Dirección: Oliver Stone. EUA: Warner Bros. Pictures / Intermedia Films, 2004. 1 DVD (173 min).

AUMONT, J.; MARIE, M. Análisis del film. Barcelona: Paidós, 1999.

AZURMENDI ADARRAGA, A. La reforma de la televisión pública española. Valencia:TirantLo Blanch, 1997.

BARROSO GARCÍA, J. Realización de los géneros televisivos. Madrid: Síntesis, 2002.

BLUM, R. A.; LINDHEIM, R. D. Programación de las cadenas de televisión en horario de máxima audiencia. Madrid: Instituto Oficial de Radio y Televisión, 1987.

BORDWELL, D.; STAIGER, J.; THOMPSON, K. El cine clásico de Hollywood: estilo cinematográfico y modo de producción hasta 1960. Barcelona: Paidós, 1997.

BURCH, N. El tragaluz del infinito (contribución a la genealogía del lenguaje cinematográfico). Madrid: Cátedra, 1985.

CORTÉS LAHERA, J. Á. La estrategia de la seducción: la programación en la neotelevisión. Pamplona: Eunsa, 2001.

CREPÚSCULO Dirección: Catherine Hardwicke. EUA: Summit Entertainment, 2008. 1 DVD (173 min).

DÉJÀ VU. Dirección: Tony Scott. EUA: Touchstone Pictures / Jerry Bruckheimer Films presentan una producción Scott Free, 2006. 1 DVD (128 min). Doblada al castellano en Tecnison S.A.
ECLIPSE. Dirección: David Slade. EUA: mprint Entertainment / Summit Entertainment, 2010. 1 DVD (124 min).

EL PACTO. Dirección: Fernando Colomo. España: Telecinco, 2010. 1 DVD (150 min).

GARCÍA DE CASTRO, M. La ficción televisiva popular: una evolución de las series de televisión en España. Barcelona: Gedisa, 2002.

GAUDREAULT, A.; JOST, F. El relato cinematográfico: cine y narratología. Barcelona: Paidós, 1995.

GECA, C. El libro de la tele: anuario de la televisión en España. Madrid: Temas de Hoy, 1995.

GENETTE, G. Figuras III. Barcelona: Lumen, 1989.

GEORGIA RULE (Lo dice Georgia). Dirección: Garry Marshall. EUA: Morgan Creek Productions, 2007.1 DVD (113 min). Doblada al castellano en EXA.

GONZÁLEZ REQUENA, J. E1 Discurso televisivo: espectáculo de la posmodernidad. Madrid: Cátedra, 1988.

HOLLYWOOD HOMICIDE (Hollywood: departamento de homicidios). Dirección: Ron Shelton. EUA: Revolution Studios, 2003. 1 DVD (111 min). Doblada al castellano en International Soundstudio.

HUERTA FLORIANO, M. Á.; SANGRO COLÓN, P. (Ed.). De los serrano a cuéntame: cómo se crean las series de televisión en España. Madrid: Arkadin, 2007.

IN THE VALLEY OF ELAH (En el Valle de Elah). Dirección: Paul Haggis, EUA: Warner Independent Pictures; Summit Entertainment, 2007. 1 DVD (120 min). Doblada al castellano en Sonoblock, S.A, Barcelona.

KRIPPENDORF, K. Metodología del análisis de contenido: teoría y práctica. Barcelona: Paidós Ibérica, 1990.

LA DUQUESA. Dirección: Salvador Calvo. España: Telecinco; Ficción Media; Gestevisión Telecinco S.A., 2010. 1 DVD (147 min).

LA PIEL AZUL. Dirección: Gonzalo López-Gallego. España: Antena 3 Filmes; Boca a Boca, 2010. 1 DVD (158 min).

NATIONAL TREASURE (La búsqueda). Dirección:Jon Turteltaub. EUA:Touchstone Pictures; Jerry Bruckheimer Films, 2004. 1 DVD (121 min). Doblada al castellano en Sonoblock, S.A. Barcelona. 
NEIRA PIÑEIRO, M. del R. Introducción al discurso narrativo fílmico. Madrid: Arco Libros, 2003.

NO SOY COMO TÚ. Dirección: Rómulo Aguillaume. España: Notro Films; A3 Fims, 2010. 1 DVD (188 min).

OJO POR OJO. Dirección: Mar Targarona. España: TVE, 2010. 180 minutos.

QUINTANA, Á. Envoltorio versus contenido. La Vanguardia, n. 44, p. 4, 2004. Suplemento.

SÁNCHEZ NAVARRO, J. Narrativa audiovisual. Barcelona: UOC, 2006.
THE CHAMBER (Cámara sellada). Dirección: James Foley. EUA: Universal Pictures; Imagine Entertainment; Brian Grazer, 1996. 113 minutos. Doblada al castellano en Sonoblock, S.A.
Recibido: 27/09/2011

Received: 09/27/2011

Aprobado: $27 / 10 / 2011$ Approved: 10/27/2011 